\title{
Current trials to reduce surgical intervention in Ductal Carcinoma in Situ of the Breast: critical review
}

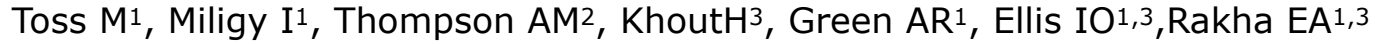 \\ 1Division of Cancer and Stem Cells, School of Medicine, University of Nottingham \\ 2Department of Surgical Oncology, University of Texas M.D. Anderson Cancer Center \\ ${ }^{3}$ Breast Institute, Nottingham University Hospitals NHS Trust, City Hospital, Nottingham UK.
}

\section{Correspondence:}

Professor Emad Rakha

Department of Histopathology, Nottingham University Hospital NHS Trust,

City Hospital Campus, Hucknall Road, Nottingham, NG5 1PB, UK

Tel: (44) 0115-9691169, Fax: (44) 0115-9627768

Email: emad.rakha@nottingham.ac.uk,Emad.rakha@nuh.nhs.uk

Running Title: Updates in DCIS management

Conflict of interest: There is no conflict of interest for this review.

Keywords: breast, duct carcinoma in situ; DCIS; management.

\section{ABSTRACT}


The high proportion of ductal carcinoma in situ (DCIS) presented in mammographic screening and the relatively low risk of progression to invasive disease have raised questions related to overtreatment. Following a review of current DCIS management protocols a more conservative approach has been suggested. Clinical trials have been introduced to evaluate the option of avoiding surgical intervention in a proportion of patients with DCIS defined as "low-risk" using certain clinicopathological criteria. These trials can potentially provide evidence-based models of active surveillance (with or without endocrine therapy) as a future management approach. Despite the undisputable fact of our need to address the obvious overtreatment of screen-detected DCIS, some important questions need to be considered regarding these trials including the eligibility criteria and definition of risk, the proportion of patient eligible for inclusion, and the length of time required for proper analysis of the trials' outcome in view of the long-term natural history of DCIS progression particularly the low-risk group. These factors can potentially affect the practicality and future impact of such trials. This review provides critical analysis of current DCIS management trials and highlights critical issues related to their practicality and the expected outcome. 


\section{INTRODUCTION}

Ductal carcinoma in situ (DCIS) refers to proliferation of malignant epithelial cells within the ducto-lobular system of the breast surrounded by a layer of myoepithelial cells and intact basement membrane [1]. The incidence of DCIS has significantly increased from less than 5\% of breast cancer $(\mathrm{BC})$ up to $20 \%$ of screen detected cancers following the introduction of mammographic screening [2, 3]. DCIS per se does not result in cancer-related mortality, however it is widely accepted that a significant proportion of DCIS lesions will progress to invasive cancer which is a potentially fatal disease. Despite limitation of the numbers and study cohort bias, available data indicates that between $14-53 \%$ of DCIS will progress to invasive carcinoma if left untreated within period of 10years or more $[4,5]$. Despite this, almost all DCIS diagnosed in routine practice are treated by ablative surgery, with or without radiotherapy, due to lack of accurate prediction of its potential progression to an invasive lesion. The latter is the result of a combination of factors including: i) the complexity of the progression process with multiple molecular and biological variables, in addition to, interplay between malignant cells and surrounding microenvironment, ii) in vitro models are not optimal for assessment of DCIS progression and, iii) almost all DCIS are treated surgically and therefore recurrence can be as a result of a new primary, underestimation of the extent of the original DCIS lesion or progression of residual initially undetected DCIS foci.

Recently, the value of population-based mammographic screening has been questioned in view of the balance between harm and benefits [6]. One important question raised is the overtreatment of screen detected lesions; some of which are unlikely to kill the patients during their 
expected lifetime, which are mainly DCIS lesions, especially in the non-high risk groups[7, 8]. This view was supported by the high prevalence of DCIS (7-39\%) found in autopsy studies of patients who died of causes other than $\mathrm{BC}$ and at age-group similar to that of population-based screening [9]providing evidence that a proportion of DCIS go undetected and does not cause significant symptoms or mortality. Other authors have questioned the legality of treating all DCIS patients with current standard methods to avoid an approximately $1 \%$ annual risk of progression to invasive disease [10]. Only half of DCIS recurrences, which are currently estimated at approximately $10-15 \%$ of all treated cases, are invasive [11, 12]. A large proportion of patients with DCIS will never develop invasive disease or die of $\mathrm{BC}$ even if left untreated. Moreover, the significant improvement in cancer molecular prognostic stratification in recent years has increased the possibility of utilising a personalised therapy approach[13, 14]; avoiding over-treatment and hence, preserving the quality of life and saving health service costs without compromising the outcomes presently achieved and limiting aggressive interventions to the high risk groups.

The current standard treatment of all DCIS lesions is complete surgical excision with or without postoperative radiotherapy $[15,16]$. Although breast conserving surgery (BCS) is widely used, there remains a high rate of surgical re-excisions or conversion to mastectomy and a proportion of patients are treated with mastectomy from the start. To reduce surgical intervention in screendetected DCIS, it has been suggested that patients with DCIS unlikely to progress to invasive disease can be subjected to active surveillance only $[11,17-20]$. Subsequently multiple clinical trials (Table 1) aimed at assessing the safety of active surveillance as an alternative to surgical intervention in the so called "low-risk" DCIS group have been introduced including i) the LOw- 
RISk DCIS (LORIS) trial, ii) the LOw Risk Dcis (LORD)trial, iii) Comparison of Operative to Monitoring and Endocrine Therapy (COMET) trial, and lastly the proposed trial; Low And intermediate RIsK ductal carcinoma IN situ study (LARRIKIN) trial. Although these trials are a way forward and the drive behind them is understandable, certain important questions should be considered to better comment on the practicality and expected outcome of these trials. These questions include: 1) have the inclusion criteria in these trials defined the low-risk group of DCIS patients precisely? 2) What is the percentage of DCIS patients who meet these criteria and to what extent will this approach be practical and rational? and, 3) What is the expected outcome that can be used as a measure of success in view of the long-term natural history of DCIS progression particularly in the low-risk group? This review addresses these trials and highlights the definition of low-risk, their practical significance and expected outcome.

\section{DCIS and risk of progression}

Accurate risk stratification and precise definition of risk in DCIS remains a challenge not only because of the complexity and multifactorial nature of the disease but also due to the lack of definition of risk when $\mathrm{BC}$ mortality is considered as the outcome measure in the setting of mammographic screening. DCIS regardless of its grade, extent or even its recurrence as an in situ disease does not have potential to cause BC mortality. Even lesions which recur as/or progress to invasive disease do not have equal risk of mortality. Some invasive cancers develop after long interval time, and are indolent; therefore are unlikely to cause mortality in a population subjected to regular screening tests. Taken together, when defining risk in DCIS, the expected 
outcome should be considered in the development of a stratification system and in guiding management decisions.

Although there is an increasing trend to define the risk using molecular profiling which can add value to current risk stratification or may be used solely in the future, these remain to be refined and validated $[14,21]$. The current risk stratification systems still rely on the more established clinicopathological parameters (Table 2). However, no single factor is sufficient on its own to define DCIS risk and a combination of multiple factors is used to stratify patients akin to invasive disease stratification. For instance patients aged more than 45 years old, with a small size DCIS (less than $15 \mathrm{~mm}$ ) that lacks comedo necrosis can be considered low-risk whereas patients with high grade lesions are considered high risk [22-24]. In addition, despite the fact that high grade DCIS is considered high-risk, only about half of them will recur or progress to invasive disease if left untreated; although there have been very few studies[4, 5].

\section{Critical view to the current management trials}

To identify patients eligible for recruitment in the DCIS active surveillance clinical trials, the established clinicopathological risk factors have been utilised, despite the known limitations, as the only available parameters. Nuclear grade has been used as the main criterion for definition of low-risk DCIS in all trials. However; low grade DCIS comprises approximately $20 \%$ of cases [9, 10] and this percent is much reduced when other inclusion criteria are considered; limiting the applicability of these trials to routine practice. In addition, cytonuclear grading of DCIS, which is the most commonly used grading method, is known to be subjective and with low concordance rates even amongst expert pathologists [25-29]. Trials based on the current simple nuclear 
grading system will be influenced by its inherent subjectivity. This view is supported by the very low number of patients recruited in the LORIS trial where only 100 patients have been recruited in the trial over 2-year period which has been reduced to 55 patients following central histopathology review prior to randomisation [30]. Other complex grading systems comparable to invasive cancer grading have been promoted [31] but are less reproducible and agreed.

However, there remains scope for an improved and reproducible DCIS morphological grading system perhaps including cytonuclear grade combined with simple biomarkers such as Estrogen Receptor (ER), HER2 and growth pattern.

Additionally, despite the strict inclusion criteria used to define low-risk DCIS in these trials, they cannot exclude the possibility of progression to invasive disease. Approximately $30 \%$ of low grade DCIS will progress to invasive disease within a period of 20 years if left untreated [32-34]. If we assume that the $30 \%$ chance of progression of low grade DCIS will be markedly reduced by the other selection criteria of the trials such as absence of necrosis (Table 1), these findings should alert us to intervals of interpretation of the trials' results. Publication of the results of the trials which typically takes place after 3-5 years of follow-up, with a maximum of 10 years, is likely to underestimate the risk of progression and can produce confusion or misinterpretation of the findings in view of such long interval time to progression. Invasive recurrence, in context of low grade DCIS, usually develops after along lag period of between 10-40 years[4, 5, 35, 36]. This creates another critical point for the practice of ongoing trials in terms of prolonged follow up periods for early detection of such progression and adds more economic and psychological burden. In addition, DCIS lesions whatever the grade are non-fatal disease, and not all high grade 
DCIS will, inevitably, progress to invasive disease. So, end points of these studies should be revised as regard progression of low grade DCIS into a higher grade DCIS lesion and surgical intervention should be applied only to lesions progress to invasive carcinoma with only close follow up could be applied for such upgraded DCIS cases. This will add to understanding the natural history of the disease and increase the number of cases remained in the study follow up periods which add to their practicality.

In contrast to a retrospective study from two UK centres investigated the adequacy of eligibility criteria for LORIS trial that showed no upgrading to invasive carcinoma after surgical excision of the tumours [37], another study showed that $20 \%$ of cases eligible for LORIS trial were upgraded to invasive carcinoma in the final pathology report and $21 \%$ of them were high grade [38]. Pilewskie, et.al. studied more than 2,500 DCIS from which 405 patients met the LORIS trial inclusion criteria and reported that $6 \%$ of these patients treated with BCS alone developed ipsilateral invasive recurrences within 10 years [39]. Other studies for treatment of low grade DCIS with excision alone without radiotherapy showed higher incidence of recurrence, including invasive recurrence, [40-42] even for those asymptomatic women detected by mammographic screening [43, 44].The Radiation Therapy Oncology Group 9804 (RTOG-9804) study reported the local recurrence rate after excision alone for low-risk DCIS patients, defined as patients with mammographic detected grade I or II lesions measured $2.5 \mathrm{~cm}$ or less with free margins at least $3 \mathrm{~mm}$. Despite, the local recurrence rate was lower in low risk group $(0.4 \%)$ than the high risk patients (3.5\%), it was significantly decreased after addition of radiotherapy following BCS, a finding that may also raise a doubt about the accuracy of the current definition of low risk patients in terms of outcome [45]. A model was developed to predict the possibility of upgrading 
DCIS lesions, diagnosed with large core biopsy, to invasive carcinoma did not find any association between grade and upgrading where $27 \%$ and $25 \%$ of grade I and grade II lesions were upgraded to invasive carcinoma after excision, respectively [46].

Inclusion criteria of these studies neglected some important parameters which can predict the presence of invasive carcinoma in initially diagnosed DCIS using core biopsy. Some studies showed that lesion size is an important factor for prediction of invasion in those patients [46-49].Models designed for DCIS diagnosed with vacuum assessed biopsies (VACB) to predict possibility of presence of invasive disease [50,51]showed that size of the lesion was the main factor in prediction of presence of invasive lesion. Supporting its prognostic value, DCIS size is one of main parameters in the Van Nuys Prognostic Index (VNPI) for prediction of recurrence [52]. Surprisingly, DCIS size was not considered in eligibility criteria for these trials except in the proposed LARRIKIN trial. Additionally, pattern of micro-calcification on mammography, even without mass formation, is important and may reflect aggressive disease which also may not be detected histologically in taken biopsy materials [53]. LORD and COMET trials clearly define that point in their eligibility criteria which is not taken into account in the other two trials.

Lastly, phenotypic and genotypic heterogeneity of DCIS lesions also provides a great challenge in risk stratification and hence in decided management approach [54]. Current trials rely mainly on VACB which provide more tissue for examination than core biopsies. However, this may not fully represent the heterogeneity of DCIS. About $16 \%$ of low nuclear grade DCIS is mixed with either intermediate or high grade foci [54-56]. Reviewing 1,059 cases of pure DCIS lesions diagnosed between 1990-2013 in Nottingham revealed that 13\% of cases were pure low nuclear 
grade while $5.5 \%$ and $1.5 \%$ of low grade lesion were mixed with intermediate or intermediate and high grades respectively (unpublished data).Therefore biopsies from multiple areas especially in large size DCIS may be warranted to ensure accurate representation.

Despite the potential prognostic value of molecular classification of DCIS, the inclusion criteria of the current trials, apart from COMET study which includes the basic biomarkers; i.e. Estrogen Receptor (ER), Progesterone Receptor (PR) and HER2, do not include molecular biomarker profiles. Molecular studies of DCIS with the Oncotype DX assay, for instance, showed that a subset of intermediate grade DCIS has high score and hence potentially have a higher risk for recurrence and progression [14]. The Eastern Cooperative Oncology Group (ECOG) E5194 study which performed to evaluate treatment of DCIS with excision alone has also shown that some of the low and intermediate grade DCIS had a high Oncotype DX score indicating that a subgroup of these morphologically low-risk DCIS have a potentially higher possibility of recurrence and progression $[57,58]$.The recent application of next generation sequencing (NGS) to investigate the molecular characterisation of DCIS is expected to improve our understanding the natural history of these lesions and may provide a more powerful tool for risk stratification of DCIS patients $[59,60]$. Although we expect more refinement of the prognostic classification of DCIS in the future, the current available molecular data may have helped to complement morphological features to identify more patient eligible for the these trials and avoid inclusion of those who are likely to progress based on morphological features alone.

Conclusions and recommendations: Although the current management approaches of DCIS, particularly the more common screen-detected lesions, can be considered overtreatment, 
at least in a proportion of cases, the precise criteria to identify low-risk patients are still not fully clear. Current trials for management low-risk DCIS by active surveillance are welcomed and is a promising approach to provide evidence-based data on such approaches as well as their role in understanding the natural history of DCIS lesions. Clarifying the limitations of such trials should be considered to increase the potential successful outcome. More precise definitions of low-risk patients including molecular profiling are needed not only to refine the classification of risk but also to increase the proportion of DCIS patients' eligible for these trials. Lesion size should be considered in inclusion criteria and multiple biopsies from large size lesions are warranted to avoid downgrading of heterogeneous lesions. In addition, the long natural history of progression of low-risk DCIS to invasive disease should be considered in terms of duration of follow-up, active surveillance period, interpretation of initial results, defining the trials end points and the expected overall outcome. Accurate and reliable interpretation of trial findings should be addressed following publications of 10,15 and even 20 years of follow-up. Recurrence as DCIS should not be considered as the final endpoint or a reason for surgical intervention but only recurrences as invasive disease should be used as an endpoint. Moreover, recurrent high grade DCIS has no mortality risk and will not inevitable progress to invasive carcinoma, so it should not be used a sign of inferiority or failure of intervention. Closer follow up for these patients may be an option. Finally, the current trials randomise between the extremes of potential management - surveillance only versus surgical ablative therapy with or without radiotherapy. Could there be potential for alternative non-invasive or minimally invasive approaches to ablation than invasive conventional surgery and could these prove to be the solution for management of low-risk breast neoplastic lesions both in-situ and invasive? 


\section{REFERENCES}

[1]Pang, J.M., K.L. Gorringe, and S.B. Fox, Ductal carcinoma in situ - update on risk assessment and management. Histopathology, 2016. 68(1): p. 96-109.

[2]Kerlikowske, K., Epidemiology of ductal carcinoma in situ. J Natl Cancer Inst Monogr, 2010. 2010(41): p. 139-41.

[3]Virnig, B.A., T.M. Tuttle, T. Shamliyan, and R.L. Kane, Ductal carcinoma in situ of the breast: a systematic review of incidence, treatment, and outcomes. J Natl Cancer Inst, 2010. 102(3): p. 170-8.

[4]Erbas, B., E. Provenzano, J. Armes, and D. Gertig, The natural history of ductal carcinoma in situ of the breast: a review. Breast Cancer Res Treat, 2006. 97(2): p. 135-44.

[5]Sanders, M.E., P.A. Schuyler, W.D. Dupont, and D.L. Page, The natural history of low-grade ductal carcinoma in situ of the breast in women treated by biopsy only revealed over 30 years of long-term follow-up. Cancer, 2005. 103(12): p. 2481-4. 
[6]Independent, U.K.P.o.B.C.S., The benefits and harms of breast cancer screening: an independent review. Lancet, 2012. 380(9855): p. 1778-86.

[7]Wood, W.C., Ductal carcinoma in situ of the breast: 'making the punishment fit the crime'. Oncology (Williston Park), 2013. 27(8): p. 796-7.

[8]Benson, J.R., I. Jatoi, and M. Toi, Treatment of low-risk ductal carcinoma in situ: is nothing better than something? Lancet Oncol, 2016. 17(10): p. e442-e451.

[9]Benson, J.R. and G.C. Wishart, Predictors of recurrence for ductal carcinoma in situ after breast-conserving surgery. The Lancet Oncology, 2013. 14(9): p. e348-e357.

[10]Groen, E.J., L.E. Elshof, L.L. Visser, E.J.T. Rutgers, H.A.O. Winter-Warnars, E.H. Lips, et al., Finding the balance between over- and under-treatment of ductal carcinoma in situ (DCIS). The Breast (2016), 2016.

[11]Elshof, L.E., K. Tryfonidis, L. Slaets, A.E. van Leeuwen-Stok, V.P. Skinner, N. Dif, et al., Feasibility of a prospective, randomised, open-label, international multicentre, phase III, non-inferiority trial to assess the safety of active surveillance for low risk ductal carcinoma in situ - The LORD study. Eur J Cancer, 2015. 51(12): p. 1497-510.

[12]Toss, M.S., S.E. Pinder, A.R. Green, J. Thomas, D.A. Morgan, J.F. Robertson, et al., Breast conservation in ductal carcinoma in situ (DCIS): what defines optimal margins? Histopathology, 2016.

[13]Rakovitch, E., S. Nofech-Mozes, W. Hanna, F.L. Baehner, R. Saskin, S.M. Butler, et al., A population-based validation study of the DCIS Score predicting recurrence risk in individuals treated by breast-conserving surgery alone. Breast Cancer Research and Treatment, 2015. 152(2): p. 389-398.

[14]Knopfelmacher, A., J. Fox, Y. Lo, N. Shapiro, and S. Fineberg, Correlation of histopathologic features of ductal carcinoma in situ of the breast with the oncotype DX DCIS score. Mod Pathol, 2015. 28(9): p. 1167-73.

[15]Lee, R.J., L.A. Vallow, S.A. McLaughlin, K.S. Tzou, S.L. Hines, and J.L. Peterson, Ductal Carcinoma In Situ of the Breast. Int J Surg Oncol, 2012. 2012.

[16]Janz, N.K., P.A. Wren, L.A. Copeland, J.C. Lowery, S.L. Goldfarb, and E.G. Wilkins, Patient-physician concordance: preferences, perceptions, and factors influencing the breast cancer surgical decision. J Clin Oncol, 2004. 22(15): p. 3091-8.

[17]Francis, A., J. Thomas, L. Fallowfield, M. Wallis, J.M. Bartlett, C. Brookes, et al., Addressing overtreatment of screen detected DCIS; the LORIS trial. Eur J Cancer, 2015. 51(16): p. 2296-303.

[18]Fallowfield, L., A. Francis, and A.M. Thompson, EFfects of standard treatments for ductal carcinoma in situ-making informed choices. JAMA Oncology, 2016. 2(3): p. 396-397.

[19]Lippey, J., A. Spillane, and C. Saunders, Not all ductal carcinoma in situ is created equal: can we avoid surgery for low-risk ductal carcinoma in situ? ANZ Journal of Surgery, 2016. 86(11): p. 859-860.

[20]Esserman, L.J., I.M. Thompson, Jr., and B. Reid, Overdiagnosis and overtreatment in cancer: an opportunity for improvement. JAMA, 2013. 310(8): p. 797-8.

[21]Kaur, H., S. Mao, S. Shah, D.H. Gorski, S.A. Krawetz, B.F. Sloane, et al., Next-Generation Sequencing: A powerful tool for the discovery of molecular markers in breast ductal carcinoma in situ. Expert review of molecular diagnostics, 2013. 13(2): p. 151-165.

[22]Di Saverio, S., F. Catena, D. Santini, L. Ansaloni, T. Fogacci, S. Mignani, et al., 259 Patients with DCIS of the breast applying USC/Van Nuys prognostic index: a retrospective review with long term follow up. Breast Cancer Res Treat, 2008. 109(3): p. 405-16.

[23]Silverstein, M.J., M.D. Lagios, P.H. Craig, J.R. Waisman, B.S. Lewinsky, W.J. Colburn, et al., A prognostic index for ductal carcinoma in situ of the breast. Cancer, 1996. 77(11): p. 2267-74.

[24]Boland, G.P., K.C. Chan, W.F. Knox, S.A. Roberts, and N.J. Bundred, Value of the Van Nuys Prognostic Index in prediction of recurrence of ductal carcinoma in situ after breastconserving surgery. Br J Surg, 2003. 90(4): p. 426-32. 
[25]Wells, W.A., P.A. Carney, M.S. Eliassen, M.R. Grove, and A.N. Tosteson, Pathologists' agreement with experts and reproducibility of breast ductal carcinoma-in-situ classification schemes. Am J Surg Pathol, 2000. 24(5): p. 651-9.

[26]Allred, D.C., Ductal carcinoma in situ: terminology, classification, and natural history. J Natl Cancer Inst Monogr, 2010. 2010(41): p. 134-8.

[27]Stasik, C.J., M. Davis, B.F. Kimler, F. Fan, I. Damjanov, P. Thomas, et al., Grading ductal carcinoma in situ of the breast using an automated proliferation index. Ann Clin Lab Sci, 2011. 41(2): p. 122-30.

[28]Silverstein, M.J., The University of Southern California/Van Nuys prognostic index for ductal carcinoma in situ of the breast. Am J Surg, 2003. 186(4): p. 337-43.

[29](WHO)., W.H.O., WHO classification of tumours of the breast. 4th Edition ed. 2012, Lyon: International Agency for Research on Cancer (IARC).

[30]Thomas, J., A. Hanby, S. Pinder, S. Pirrie, D. Rea, C. Gaunt, et al., Abstract P3-17-06: LORIS trial of active monitoring for DCIS: How does the online pathology eligibility review process work? Cancer Research, 2017. 77(4 Supplement): p. P3-17-06-P3-17-06.

[31]Holland, R., J.L. Peterse, R.R. Millis, V. Eusebi, D. Faverly, M.J. Vandevijver, et al., Ductal Carcinoma in Situ: A Proposal For a New Classification. Seminars in Diagnostic Pathology, 1994. 11(3): p. 167-180.

[32]Liao, S., M.M. Desouki, D.P. Gaile, L. Shepherd, N.J. Nowak, J. Conroy, et al., Differential copy number aberrations in novel candidate genes associated with progression from in situ to invasive ductal carcinoma of the breast. Genes Chromosomes Cancer, 2012. 51(12): p. 1067-78.

[33]Allred, D.C., Y. Wu, S. Mao, I.D. Nagtegaal, S. Lee, C.M. Perou, et al., Ductal carcinoma in situ and the emergence of diversity during breast cancer evolution. Clin Cancer Res, 2008. 14(2): p. 370-8.

[34]Vuong, D., P.T. Simpson, B. Green, M.C. Cummings, and S.R. Lakhani, Molecular classification of breast cancer. Virchows Archiv, 2014. 465(1): p. 1-14.

[35]Kerlikowske, K., A. Molinaro, I. Cha, B.M. Ljung, V.L. Ernster, K. Stewart, et al., Characteristics associated with recurrence among women with ductal carcinoma in situ treated by lumpectomy. J Natl Cancer Inst, 2003. 95(22): p. 1692-702.

[36]Ringberg, A., H. Nordgren, S. Thorstensson, I. Idvall, H. Garmo, B. Granstrand, et al., Histopathological risk factors for ipsilateral breast events after breast conserving treatment for ductal carcinoma in situ of the breast--results from the Swedish randomised trial. Eur J Cancer, 2007. 43(2): p. 291-8.

[37]Soumian, S., E.T. Verghese, M. Booth, N. Sharma, S. Chaudhri, S. Bradley, et al., Concordance between vacuum assisted biopsy and postoperative histology: implications for the proposed Low Risk DCIS Trial (LORIS). Eur J Surg Oncol, 2013. 39(12): p. 1337-40.

[38]Pilewskie, M., M. Stempel, H. Rosenfeld, A. Eaton, K.J. Van Zee, and M. Morrow, Do LORIS Trial Eligibility Criteria Identify a Ductal Carcinoma In Situ Patient Population at Low Risk of Upgrade to Invasive Carcinoma? Ann Surg Oncol, 2016. 23(11): p. 3487-93.

[39]Pilewskie, M., C. Olcese, S. Patil, and K.J. Van Zee, Women with Low-Risk DCIS Eligible for the LORIS Trial After Complete Surgical Excision: How Low Is Their Risk After Standard Therapy? Ann Surg Oncol, 2016. 23(13): p. 4253-4261.

[40]Khan, S., M. Epstein, M.D. Lagios, and M.J. Silverstein, Are We Overtreating Ductal Carcinoma in Situ (DCIS)? Ann Surg Oncol, 2016.

[41]Kim, H., J.M. Noh, D.H. Choi, J. Lee, S.J. Nam, J.E. Lee, et al., Excision alone for small size ductal carcinoma in situ of the breast. Breast, 2014. 23(5): p. 586-90.

[42]Solin, L.J., Is excision alone adequate treatment for low-risk ductal carcinoma-in-situ of the breast? J Clin Oncol, 2006. 24(7): p. 1017-9.

[43]Kestin, L.L., N.S. Goldstein, A.A. Martinez, M. Rebner, M. Balasubramaniam, R.C. Frazier, et al., Mammographically detected ductal carcinoma in situ treated with conservative surgery with or without radiation therapy: patterns of failure and 10-year results. Ann Surg, 2000. 231(2): p. 235-45. 
[44]Shah, C., F.A. Vicini, S. Berry, T.B. Julian, J.B. Wilkinson, S.F. Shaitelman, et al., Ductal Carcinoma In Situ of the Breast: Evaluating the Role of Radiation Therapy in the Management and Attempts to Identify Low-risk Patients. Am J Clin Oncol, 2015. 38(5): p. 526-33.

[45]McCormick, B., K. Winter, C. Hudis, H.M. Kuerer, E. Rakovitch, B.L. Smith, et al., RTOG 9804: a prospective randomized trial for good-risk ductal carcinoma in situ comparing radiotherapy with observation. J Clin Oncol, 2015. 33(7): p. 709-15.

[46]Diepstraten, S.C.E., S.M.W.Y. van de Ven, R.M. Pijnappel, P.H.M. Peeters, M.A.A.J. van den Bosch, H.M. Verkooijen, et al., Development and Evaluation of a Prediction Model for Underestimated Invasive Breast Cancer in Women with Ductal Carcinoma In Situ at Stereotactic Large Core Needle Biopsy. PLoS One, 2013. 8(10): p. e77826.

[47]Kondo, T., N. Hayashi, S. Ohde, K. Suzuki, A. Yoshida, H. Yagata, et al., A model to predict upstaging to invasive carcinoma in patients preoperatively diagnosed with ductal carcinoma in situ of the breast. J Surg Oncol, 2015. 112(5): p. 476-80.

[48]Coufal, O., I. Selingerova, P. Vrtelova, P. Krsicka, L. Gabrielova, P. Fabian, et al., A simple model to assess the probability of invasion in ductal carcinoma in situ of the breast diagnosed by needle biopsy. Biomed Res Int, 2014. 2014: p. 480840.

[49]Doebar, S.C., C. de Monye, H. Stoop, J. Rothbarth, S.P. Willemsen, and C.H. van Deurzen, Ductal carcinoma in situ diagnosed by breast needle biopsy: Predictors of invasion in the excision specimen. Breast, 2016. 27: p. 15-21.

[50]Houssami, N., D. Ambrogetti, M.L. Marinovich, S. Bianchi, P. Macaskill, V. Vezzosi, et al., Accuracy of a preoperative model for predicting invasive breast cancer in women with ductal carcinoma-in-situ on vacuum-assisted core needle biopsy. Ann Surg Oncol, 2011. 18(5): p. 1364-71.

[51]Gumus, H., P. Mills, D. Fish, M. Gumus, K. Cox, H. Devalia, et al., Predictive factors for invasive cancer in surgical specimens following an initial diagnosis of ductal carcinoma in situ after stereotactic vacuum-assisted breast biopsy in microcalcification-only lesions. Diagn Interv Radiol, 2016. 22(1): p. 29-34.

[52]Silverstein, M.J. and M.D. Lagios, Treatment selection for patients with ductal carcinoma in situ (DCIS) of the breast using the University of Southern California/Van Nuys (USCI VNPI) prognostic index. Breast J, 2015. 21(2): p. 127-32.

[53]Szynglarewicz, B., P. Kasprzak, P. Biecek, A. Halon, and R. Matkowski, Screen-detected ductal carcinoma in situ found on stereotactic vacuum-assisted biopsy of suspicious microcalcifications without mass: radiological-histological correlation. Radiol Oncol, 2016. 50(2): p. 145-52.

[54]Mokbel, K. and B. Cutuli, Heterogeneity of ductal carcinoma in situ and its effects on management. The Lancet Oncology. 7(9): p. 756-765.

[55]Quinn, C.M. and J.L. Ostrowski, Cytological and architectural heterogeneity in ductal carcinoma in situ of the breast. J Clin Pathol, 1997. 50(7): p. 596-599.

[56]Lagios, M.D., Heterogeneity of duct carcinoma in situ (DCIS): relationship of grade and subtype analysis to local recurrence and risk of invasive transformation. Cancer Lett, 1995. 90(1): p. 97-102.

[57]Hughes, L.L., M. Wang, D.L. Page, R. Gray, L.J. Solin, N.E. Davidson, et al., Local excision alone without irradiation for ductal carcinoma in situ of the breast: a trial of the Eastern Cooperative Oncology Group. J Clin Oncol, 2009. 27(32): p. 5319-24.

[58]Solin, L.J., R. Gray, F.L. Baehner, S.M. Butler, L.L. Hughes, C. Yoshizawa, et al., A multigene expression assay to predict local recurrence risk for ductal carcinoma in situ of the breast. J Natl Cancer Inst, 2013. 105(10): p. 701-10.

[59]King, L., J. Marks, A. Hall, D. Temko, T. Graham, E. Mardis, et al., Abstract P6-05-03: Genomic diversity of ductal carcinoma in situ (DCIS) as a driver of invasion and metastasis. Cancer Research, 2016. 76(4 Supplement): p. P6-05-03-P6-05-03.

[60]Kaur, H., S. Mao, S. Shah, D.H. Gorski, S.A. Krawetz, B.F. Sloane, et al., Next-generation sequencing: a powerful tool for the discovery of molecular markers in breast ductal carcinoma in situ. Expert Rev Mol Diagn, 2013. 13(2): p. 151-65. 
[61]Kuerer, H.M. and R.F. van la Parra, Breast Cancer Clinical Trials: Past Half Century Moving Forward Advancing Patient Outcomes. Ann Surg Oncol, 2016.

[62]Kong, I., S.A. Narod, C. Taylor, L. Paszat, R. Saskin, S. Nofech-Moses, et al., Age at diagnosis predicts local recurrence in women treated with breast-conserving surgery and postoperative radiation therapy for ductal carcinoma in situ: a population-based outcomes analysis. Curr Oncol, 2014. 21(1): p. e96-e104.

[63]Tunon-de-Lara, C., G. Andre, G. Macgrogan, J.M. Dilhuydy, J.E. Bussieres, M. Debled, et al., Ductal carcinoma in situ of the breast: influence of age on diagnostic, therapeutic, and prognostic features. Retrospective study of 812 patients. Ann Surg Oncol, 2011. 18(5): p. 1372-9.

[64]Vicini, F.A., S. Shaitelman, J.B. Wilkinson, C. Shah, H. Ye, L.L. Kestin, et al., Long-term impact of young age at diagnosis on treatment outcome and patterns of failure in patients with ductal carcinoma in situ treated with breast-conserving therapy. Breast J, 2013. 19(4): p. 365-73.

[65]Koh, V.C., J.C. Lim, A.A. Thike, P.Y. Cheok, M.M. Thu, V.K. Tan, et al., Characteristics and behaviour of screen-detected ductal carcinoma in situ of the breast: comparison with symptomatic patients. Breast Cancer Res Treat, 2015. 152(2): p. 293-304.

[66]Cheung, S., M.E. Booth, O. Kearins, and D. Dodwell, Risk of subsequent invasive breast cancer after a diagnosis of ductal carcinoma in situ (DCIS). Breast, 2014. 23(6): p. 807-11.

[67]Zhang, X., H. Dai, B. Liu, F. Song, and K. Chen, Predictors for local invasive recurrence of ductal carcinoma in situ of the breast: a meta-analysis. Eur J Cancer Prev, 2016. 25(1): p. 19-28.

[68]McCormick, B., P.P. Rosen, D. Kinne, L. Cox, and J. Yahalom, Duct carcinoma in situ of the breast: an analysis of local control after conservation surgery and radiotherapy. Int J Radiat Oncol Biol Phys, 1991. 21(2): p. 289-92.

[69]Zhou, W., H. Pan, M. Liang, K. Xia, X. Liang, J. Xue, et al., Family history and risk of ductal carcinoma in situ and triple negative breast cancer in a Han Chinese population: a case-control study. World J Surg Oncol, 2013. 11: p. 248.

[70]Vicini, F.A., L.L. Kestin, N.S. Goldstein, K.L. Baglan, J.E. Pettinga, and A.A. Martinez, Relationship between excision volume, margin status, and tumor size with the development of local recurrence in patients with ductal carcinoma-in-situ treated with breast-conserving therapy. J Surg Oncol, 2001. 76(4): p. 245-54.

[71]Meijnen, P. and H. Bartelink, Multifocal ductal carcinoma in situ of the breast: a contraindication for breast-conserving treatment? J Clin Oncol, 2007. 25(35): p. 5548-9.

[72]Wai, E.S., M.L. Lesperance, C.S. Alexander, P.T. Truong, P. Moccia, M. Culp, et al., Predictors of Local Recurrence in a Population-Based Cohort of Women with Ductal Carcinoma In Situ Treated with Breast Conserving Surgery Alone. Ann Surg Oncol, 2010. 18(1): p. 119-124.

[73]Wai, E.S., M.L. Lesperance, C.S. Alexander, P.T. Truong, P. Moccia, M. Culp, et al., Predictors of local recurrence in a population-based cohort of women with ductal carcinoma in situ treated with breast conserving surgery alone. Ann Surg Oncol, 2011. 18(1): p. 119-24.

[74]Warnberg, F., J. Bergh, M. Zack, and L. Holmberg, Risk factors for subsequent invasive breast cancer and breast cancer death after ductal carcinoma in situ: a populationbased case-control study in Sweden. Cancer Epidemiol Biomarkers Prev, 2001. 10(5): p. 495-9. 

Table 1 Current trials comparing management of DCIS by active surveillance against surgical treatment 


\begin{tabular}{|c|c|c|c|c|c|}
\hline Study & Inclusion criteria & Exclusion criteria & $\begin{array}{l}\text { P a t i e n t s } \\
\text { recruitment }\end{array}$ & $\begin{array}{l}\text { Main End } \\
\text { points }\end{array}$ & $\begin{array}{l}\text { Number } \\
0 \quad \text { f } \\
\text { patients } \\
\text { required }\end{array}$ \\
\hline $\begin{array}{l}\text { The Low-risk } \\
\text { D C I S Trial } \\
\text { ( L O R I S } \\
\text { TRIAL) [17] } \\
\text { (UK study) }\end{array}$ & $\begin{array}{l}\text { * Female, aged } 46 \text { years } \\
\text { or more } \\
\text { * Non high grade DCIS } \\
\text { (uni- or bilateral) } \\
\text { detected through } \\
\text { S c r e n i ng } \\
\text { mammograph or } \\
\text { incidental micro- } \\
\text { calcification and } \\
\text { c o n i r m e d } \\
\text { histologically through } \\
\text { Vacuum Assisted Core } \\
\text { Biopsy (VACB) or } \\
\text { VACB plus ope n } \\
\text { diagnostic surgical } \\
\text { biopsy (without clear } \\
\text { margins) } \\
* \text { Patients should be } \\
\text { able to give informed } \\
\text { consent and fit to } \\
\text { undergo surgery }\end{array}$ & $\begin{array}{l}\text { * Previous or current } \\
\text { invasive breast cancer or } \\
\text { previous ipsilateral } \\
\text { DCIS (i.e. recurrent } \\
\text { DCIS) } \\
\text { * Symptomatic patient } \\
\text { with a mass lesion or } \\
\text { blood stained nipple } \\
\text { disch arge without } \\
\text { evidence of benign } \\
\text { lesion } \\
\text { * Histologically detected } \\
\text { unequivocal comedo } \\
\text { necrosis } \\
\text { * Patients at high risk for } \\
\text { developing invasive } \\
\text { breast cancer (as defined } \\
\text { in NICE guidelines for } \\
\text { familial breast cancer or } \\
\text { due to previous exposure } \\
\text { to radiotherapy) }\end{array}$ & July 2014 & $\begin{array}{l}\text { Occurrence } \\
\text { of ipsilateral } \\
\text { in a s ive } \\
\text { breast cancer } \\
\mathrm{w} \text { i t h i n } \\
\text { follow up } \\
\text { period of } 10 \\
\text { years. }\end{array}$ & 932 \\
\hline $\begin{array}{l}\text { Low-risk Dcis } \\
\text { Trial (LORD) } \\
\text { trial [11] } \\
\text { (Europe Study) }\end{array}$ & 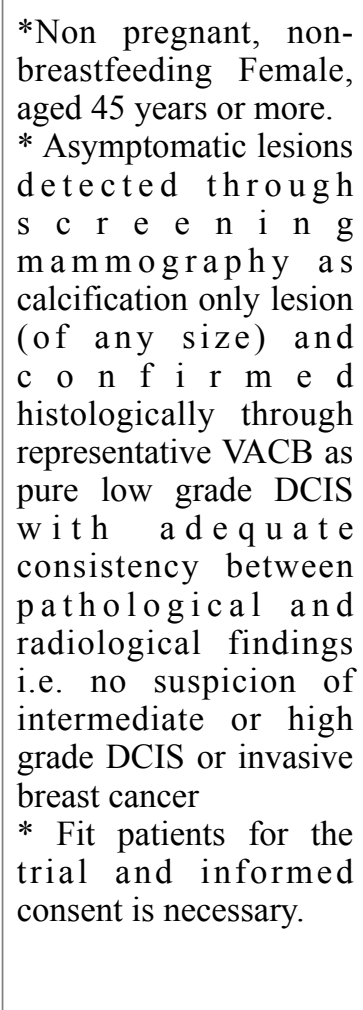 & $\begin{array}{l}\text { * Symptomatic DCIS } \\
\text { either with mass, nipple } \\
\text { discharge or lesions with } \\
\text { marked architecture } \\
\text { d i s t o r t i o n o n } \\
\text { mammography. } \\
\text { * Bilateral DCIS or } \\
\text { those associated with } \\
\text { Paget's dise a se or } \\
\text { lobular neoplasia } \\
\text { * P r e v i o u s or } \\
\text { synchronous invasive } \\
\text { breast carcinoma in the } \\
\text { contralateral breast or } \\
\text { previous history of DCIS } \\
\text { in any side } \\
\text { * Patients unfit for trial } \\
\text { due to serious disease or } \\
\text { have previous history for } \\
\text { malignancy (apart from } \\
\text { carcinoma in situ of the } \\
\text { cervix or basal cell } \\
\text { carcinoma of the skin). } \\
\text { * Individual from a } \\
\text { family with a known } \\
\text { BRCA1/2 mutation }\end{array}$ & Not yet & $\begin{array}{l}\text { Occurrence } \\
\text { of ipsilateral } \\
\text { i n a s i ve } \\
\text { breast cancer } \\
\text { or higher } \\
\text { grade DCIS } \\
\text { (grade II or } \\
\text { III) within } \\
\text { follow up } \\
\text { period of } 10 \\
\text { years. }\end{array}$ & 1240 \\
\hline
\end{tabular}




\begin{tabular}{|c|c|c|c|c|c|}
\hline $\begin{array}{l}\text { Comparison of } \\
\text { Operative to } \\
\text { Monitoring and } \\
\text { Endocrine } \\
\text { Therapy } \\
\text { (COMET) Trial } \\
\text { For Low-risk } \\
\text { DCIS [61] } \\
\text { (USA Study) }\end{array}$ & $\begin{array}{l}\text { * Non-pregnant } \\
\text { Female, aged } 40 \text { years } \\
\text { or more } \\
\text { * Pure unifocal or } \\
\text { multifocal low or } \\
\text { intermediate DCIS } \\
\text { (uni- or bilateral) } \\
\text { without comedo } \\
\text { necrosis diagnosed } \\
\text { histologically by needle } \\
\text { core biopsy (from } 2 \\
\text { sites of lesions measure } \\
\text { more than } 4 \mathrm{~cm}) \text {. } \\
\text { * Lesions should be } \\
\text { Estrogen Receptor (ER) } \\
(+) \text { and/or Progesterone } \\
\text { Receptor (PR) }(+) \text { by } \\
\text { Immunohistochemistry } \\
\text { (IHC) }(\geq 10 \% \text { staining } \\
\text { or Allred score } \geq 4) \text { and } \\
\text { negative for HER } 2 / \text { neu } \\
\text { * No previous history } \\
\text { of breast cancer in } \\
\text { either breast } \\
\text { * Fit patients for the } \\
\text { trial and surgery } \\
\text { confirmed with normal } \\
\text { baseline blood tests and } \\
\text { renal functions. } \\
\text { * Informed constant }\end{array}$ & $\begin{array}{l}\text { * Previous or concurrent } \\
\text { invasive breast cancer, or } \\
\text { previous history of } \\
\text { usages anti oestrogens } \\
\text { * Symptomatic cases } \\
\text { with mass formed } \\
\text { lesions or bloody nipple } \\
\text { discharge } \\
\text { * Suspicious of invasive } \\
\text { disease in } \\
\text { mammography } \\
\text { * Unfit patients with } \\
\text { serious diseases }\end{array}$ & Not yet & $\begin{array}{l}\text { Occurrence } \\
\text { of ipsilateral } \\
\text { i n v a s i v e } \\
\text { breast cancer } \\
\text { or higher } \\
\text { grade DCIS } \\
\text { (grade II or } \\
\text { III) within } \\
\text { follow up } \\
\text { period of } 5 \\
\text { years. }\end{array}$ & 1189 \\
\hline $\begin{array}{l}\text { Low And } \\
\text { InteRmediate } \\
\text { RIsK ductal } \\
\text { carcinoma IN } \\
\text { situ study } \\
\text { (LARRIKIN) } \\
\text { Trial [10]. } \\
\text { Australian } \\
\text { Study }\end{array}$ & $\begin{array}{l}\text { * Non pregnant, non- } \\
\text { lactating Female, aged } \\
55 \text { years or more } \\
\text { * Pure, asymptomatic } \\
\text { screen detected uni- or } \\
\text { bilateral, unifocal DCIS } \\
\text { (low and intermediate } \\
\text { grade) measures } 2 \mathrm{~cm} \text { or } \\
\text { less based on either a } \\
\text { core biopsy and/or } \\
\text { VACB or open } \\
\text { diagnostic surgical } \\
\text { biopsy. }\end{array}$ & $\begin{array}{l}\text { * No previous or current } \\
\text { diagnosis of invasive } \\
\text { cancer, previous } \\
\text { ipsilateral } \\
\text { DCIS, Paget's disease or } \\
\text { LCIS, } \\
\text { *Patients with BRCA } 1 / 2 \\
\text { mutation }\end{array}$ & $\begin{array}{l}\text { Not yet } \\
\text { (proposed } \\
\text { t r a i } 1 ; \\
\text { f u n d i g } \\
\text { requirement } \\
\text { submitted) }\end{array}$ & $\begin{array}{l}\text { Occurrence } \\
\text { of ipsilateral } \\
\text { in a s i v e } \\
\text { breast cancer } \\
\text { or higher } \\
\text { grade DCIS } \\
\text { (grade II or } \\
\text { III) within } \\
\text { follow up } \\
\text { period of } 5 \\
\text { years. }\end{array}$ & 550 \\
\hline
\end{tabular}


Table 2 Pre-operative risk factors of DCIS recurrence and progression

\begin{tabular}{|l|l|l|}
\hline Factor & Risk & References \\
\hline Age & $\begin{array}{l}\text { The risk of DCIS invasive recurrence is } \\
\text { 2-3 folds in patients younger than 50 } \\
\text { years }\end{array}$ & {$[62-64]$} \\
\hline Symptomatic patient & $\begin{array}{l}\text { Symptomatic DCIS has higher risk for } \\
\text { invasive recurrence than screen-detected } \\
\text { patients }\end{array}$ & {$[65-67]$} \\
\hline Family history & $\begin{array}{l}\text { Patients with positive family history of } \\
\text { breast cancer are more liable for invasive } \\
\text { recurrence after treatment of DCIS }\end{array}$ & {$[21,68,69]$} \\
\hline DCIS size and focality & $\begin{array}{l}\text { Large size (more than 4cm) and/or } \\
\text { multifocal DCIS lesions have higher risk } \\
\text { for recurrence than small sized }\end{array}$ & {$[67,70,71]$} \\
\hline Tumour grade & $\begin{array}{l}\text { High grade DCIS are more likely to } \\
\text { recur; mainly invasive; than low grade } \\
\text { one }\end{array}$ & {$[21,67,72,73]$} \\
\hline Comedo necrosis & $\begin{array}{l}\text { Lesions associated with comedo necrosis } \\
\text { have higher incidence of recurrence } \\
\text { especially invasive recurrence }\end{array}$ & {$[67,74]$} \\
\hline Molecular subtypes & $\begin{array}{l}\text { Lesions with HER2 positivity are at high } \\
\text { risk for tumour recurrence }\end{array}$ & {$[21]$} \\
\hline
\end{tabular}

